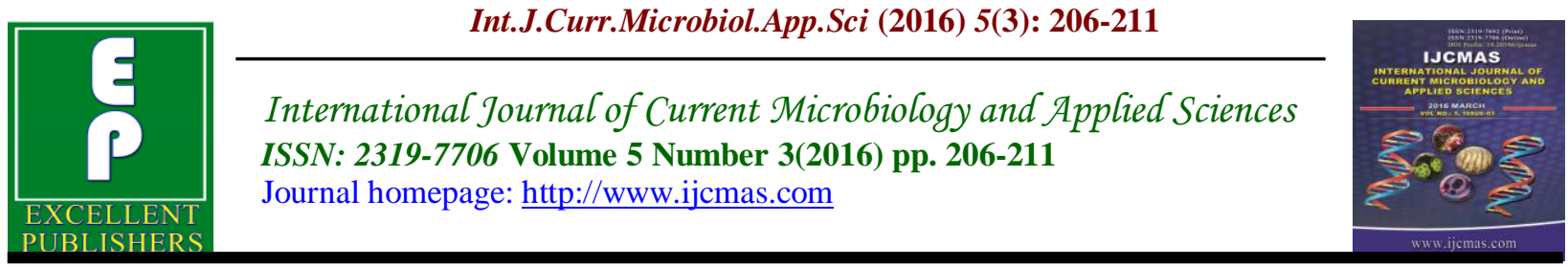

Original Research Article

http://dx.doi.org/10.20546/ijcmas.2016.503.025

\title{
Rotaviral Diarrhoea in Children Less than 5 years with Reference to their Vaccination Status in a Tertiary Care Hospital
}

\section{Introduction}

Diarrheal diseases are major causes of hospitalizations and child deaths globally. They account for approximately one in six deaths among children younger than five years

(Black RE et al).WHO and UNICEF data shows 2 billion cases of diarrheal diseases worldwide every year (Bass CW et al). 1.9 million children less than 5 years perish every year from diarrhea. $18 \%$ of all deaths in children less than 5 years is due to diarrhea.
More than 5000 children die every day \& constitutes $78 \%$ of the burden in Africa and South East Asia (Bassani DG et al., Parashar UD et al).

In India, annually about 2.3 million deaths occur in children in children less than 5years. Diarrheal diseases are the cause for 3,34,000 of them (Black RE et al., Parashar UD et al). Rotavirus is the leading cause of severe diarrhea in children in developed as well as developing countries (CDC 2008). Rotavirus infects almost all children 
by the age of five, both in the developing and developed countries (WHO 2005 guidelines). It has been estimated that per day, 370000 episodes of rotavirus diarrhea occur, 50,000 cases are hospitalized and 2000 die in the world (Zheng BJ et al). In India, about 20-30 per cent of hospitalized diarrhea cases are caused by Rotavirus gastroenteritis in infants and young children during winter months (Nath $\mathrm{G}$ et al).

Rotavirus belongs to family Reoviridae, genome of the virus consists of 11 segments of double stranded linear molecule of RNA. There are seven rotavirus groups (A to $G$ ). Only groups $\mathrm{A}, \mathrm{B}$, and $\mathrm{C}$ infect humans. Group A, which has multiple strains, causes the majority of childhood infections (Zheng BJ et al., Phukan AC et al). Although human of all ages are susceptible to rotavirus infection, children 3 to 24 months of age account for the vast majority of severe infections (Ram S et al). The illness usually lasts 3-8 days, but virus shedding continues for about 10 days to 1 month (Barnes GL et al).

Clinically, Rotavirus gastroenteritis is characterized by profuse diarrhea, mild fever and vomiting, leading from mild to severe dehydration (Bon $\mathrm{F}$ et al). The clinical manifestations of Rotavirus diarrhea alone are not sufficiently distinctive to permit diagnosis. It is observed that children below 5 years of age who were hospitalized for severe diarrhea showed positivity for Rotavirus. Realizing that Rotavirus causes severe diarrhea, it is desirable to devise rapid, easy and cost effective methods it's for detection (Versalovic $\mathrm{J}$ et al).

Rotavirus can be detected by single step rapid test, Enzyme linked immunosorbent assay, Lattice agglutation test, Ribonucleic acid - Polyacrylamide gel electrophoresis \& Polymerase chain reaction (PCR) (WHO guidelines 1997). Early detection of
Rotaviral diarrheal diseases will reduce indigenous use of antibiotics, development of resistance. Also, to initiate Rotavirus vaccination which prevents hospitalization and the fatality of disease (Kelkar SD et al).

Currently two rotavirus vaccines have been shown to be effective against rotavirus and have been licensed in more than 100 countries, including India (Bahl $\mathrm{R}$ et al). In the present study children less than 5 years of age were evaluated for rotavirus diarrheal diseases using Standard diagnostic Bioline Rotavirus stool antigen kit. This study was taken up to find out the occurrence of Rota viral diarrhea at our institute.

\section{Materials and Methods}

This prospective study was conducted between June 2014 to November 2014 at Rajarajeswari medical college \& hospital, Bengaluru. Permission for conducting this study was obtained from the Institutional Ethical Committee. A single stool sample was collected from 191 infants and children less than 5 years hospitalized in pediatrics ward for diarrheal diseases were included in present study. Vaccination history against Rotavirus was duly noted. All diarrheal cases above 5 years were excluded.Stool samples were collected using sterile plastic containers \& were transported as early as possible to the laboratory for analysis and the in case of delay samples were refrigerated at $4^{0} \mathrm{C}$.

Methodology: A Rapid test one-step lateral flow immunochromatographic assay that detects group A Rotavirus was detected using Standard Diagnostic Bioline Rotavirus stool antigen kit. This kit used colloidal gold-labeled monoclonal antibodies against the capsid protein of gene 6 (VP6) of rotaviruses. Test procedure was done as per manufacture's instruction. 


\section{Results and Discussion}

Among 191 stool samples collected 134 stool samples were from children less than 2 years of age group \& 57 stool samples were from children between 2-5 years as shown in Table 1.

134 patients belonged to less than 2 years of age, of which $83(43.4 \%)$ were predominantly male. The remaining 57 (29.9\%) years were in the 2 to 5 of age group.

Table 2 shows 64 (82\%) cases were Rotavirus positive in patients less than 2 years of age as compared to $14(18 \%)$ in patients of 2-5 years of age. This indicates the higher number of cases occurring in patients below 2 years of age.

Table 3 show that of the 67 unimmunized patients $64 \quad(70.3 \%)$ had developed Rotavirus diarrhea. Whereas the 67 immunized patients were Rotavirus positive.

Worldwide Rotaviral gastroenteritis is responsible for 611,000 childhood deaths out of which more than $80 \%$ occur in lowincome countries (Bahl R et al). Rotavirus is the most important cause of early childhood nonbacterial gastroenteritis in both developed and developing countries.The infection is also observed in older children and adults. In developed countries $50 \%$ of pediatric hospitalization are due to acute diarrhea, while in developing countries like India, it is responsible for an estimated one million deaths annually (Paramita SG). Of the approximately 600,000 annual deaths due to rotavirus worldwide, more than 150,000 occur in India (Bass CW et al., Bassani DG et al). Also, 20 to 30 percent hospitalized cases of diarrhea are due to rotaviruses (Parashar UD et al., Bassani DG et al). It is estimated that Rotavirus is responsible for 24 million outpatient visits,
2.4 million hospital visits and 6,11,000 deaths annually with 80 per cent of these taking place in poorer countries (zafer $\mathrm{K}$ et al). In India, 350,000 children, under 5 die every year due to acute diarrheal diseases, out of which one third of them is due to Rotavirus gastroenteritis. The prevalence of Rotavirus diarrhea in India has been found to vary between 7 to $71 \%$ in hospitalized children less than 5 years of age with acute gastroenteritis (Ayman $\mathrm{J}$ et al).

In our study rotavirus diarrhea was seen in children less than 5 years is (78) $40.8 \%$ which is in close correlation with study by Jain $\mathrm{V}$ et al \& Gazal $\mathrm{S}$ et al study, who showed $41 \%$ \& $41.9 \%$ (Jane S et al., Bettina $\mathrm{E}$ et al). In earlier studies, prevalence rate of rotavirus diarrhea in children was ranging from $33.3 \%$ in 1995 to $19.0 \%$ in 1998 (Bahl $\mathrm{R}$ et al). Few other short and long term studies from other parts of India has revealed varying rates of prevalence that ranged from as low as 4 to $62.6 \%$ (Kelkar $\mathrm{SD}$ et al., Bahl R et al., Paramita SG, zafer $\mathrm{K}$ et al., Jane $\mathrm{S}$ et al., Bettina $\mathrm{E}$ et al.). These wide ranges obviously reflect differences in age group studied, detection methods employed, geographical location, time of onset and duration of the investigation (Kelkar SD et al., Jane S et al).

In our study, table 1 shows 128 (67\%) stool samples were from male patients among them $62(48.6 \%)$ were positive for Rotavirus. Out of $63(33 \%)$ female patients stool samples $16(25.3 \%)$ were positive for Rotavirus. Male patient's incidence is up to $22 \%$ higher than that of female patients, which correlates with Shetty Ak et al who showed $23(65.71 \%)$ males \& $12(34.2 \%)$ female patients. This is due to a greater susceptibility of exposure to Rotavirus diarrheal disease in male children and higher likelihood of them being brought for medical care (Patwari AK et al.,). 
Table.1 Demographic Distribution of Diarrheal Cases

\begin{tabular}{|l|c|c|l|}
\hline Age group & Male $(\%)$ & Female $(\%)$ & Total $(\%)$ \\
\hline Less than 2 years & $83(43.4 \%)$ & $51(26.7 \%)$ & $134(70.1 \%)$ \\
\hline Between 2-5 years & $45(23.5 \%)$ & $12(6.2 \%)$ & $57(29.9 \%)$ \\
\hline Total & $128(67.1 \%)$ & $63(32.9 \%)$ & $191(100 \%)$ \\
\hline
\end{tabular}

Table.2 Rotavirus Positive Cases in Children

\begin{tabular}{|l|l|l|}
\hline Diarrheal cases & Total number & Number of positive \\
\hline Less than 2 years & $134(70.1 \%)$ & $64(82 \%)$ \\
\hline Between 2-5 years & $57(29.9 \%)$ & $14(18 \%)$ \\
\hline
\end{tabular}

Table.3 Total Number of Immunized and Unimmunized Children

\begin{tabular}{|l|l|l|l|l|}
\hline \multirow{2}{*}{ Age group } & \multicolumn{2}{|l|}{ Immunized } & \multicolumn{2}{l|}{ unimmunized } \\
\hline \multirow{2}{*}{ Less than 2 years } & Total & Rv positive & Total & Rv positive \\
\cline { 2 - 5 } & 67 & $0(0 \%)$ & 67 & $64(70.3 \%)$ \\
\hline More than 2 years & 33 & $0(0 \%)$ & 24 & $14(15.4 \%)$ \\
\hline Total & 100 & $0(0 \%)$ & 91 & $78(85.7 \%)$ \\
\hline
\end{tabular}

Figure.1 Shows Sd Rapid Test Card and Diluents, Positive Test is Seen

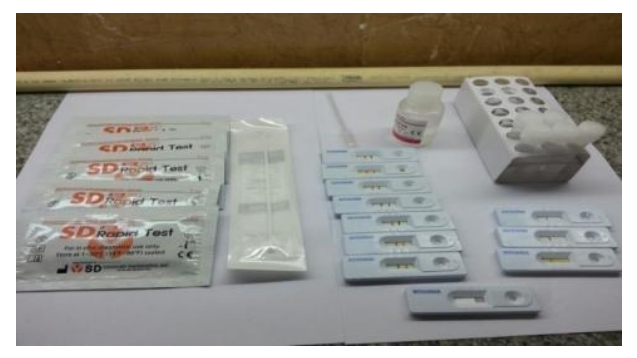

Figure.2 Shows Negative Card Test with Red Band in Control Line

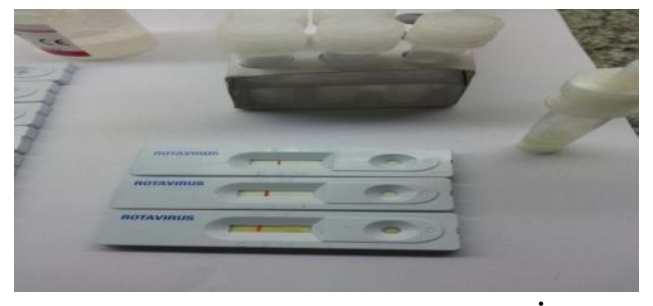

\section{Seasonal Variations}

Rotavirus diarrhea was seen all through the year, an increase was noted during the rainy and winter season i.e. in the months of June to November. This has correlated with the other studies Nath et al., , Phukan et al., \& 
Bahl R et al., where the peak of rotavirus diarrhea in winter,as humid conditions facilitate rotavirus survival \& replication on surfaces (zafer $\mathrm{K}$ et al.,., Chatterjee B et al.,).

Among 191 stool sample as shown in table 2, 134 (70.1\%) of Rotavirus cases were seen in children less than 2 years of age group which is in close comparison with Patwari Ak et al., who have shown 25 (71.43\%).It appeared that infants below 6 months of age were initially protected to some extent by maternal antibodies against severe diarrhea due to Rotavirus (Brown DW et al., Broor S et al).

Our study showed $78(85.7 \%)$ positivity for Rotavirus in 91 unimmunized patients in table 3. Thus showing Rotavirus vaccination reduces the Rota viral diarrhea in of children less than 5 years. It would help reduce the global burden of acute diarrheal diseases. Widespread use of Rotavirus vaccines can prevent about 2 million deaths over next decade (Selim A et al., Jain V et al).

Immunochromatography is a rapid simple diagnostic tool which can be as a bed side test, does not require skilled person.

Limitation of our study: cannot be used to differentiate between serotypes of Rotavirus less sensititive than PCR.

In conclusion, this study highlights that Rotavirus diarrhea accounts for a large proportion of diarrheal disease in hospitalized children less than 5 years in Bengaluru and it is seen more during winter months of the year.

To routinely immunize against Rotavirus thereby reduce the morbidity \& mortality due to Rotavirus in children. Thus it prevents hospitalization and fatality associated with Rotavirus gastroenteritis.

\section{Acknowledgement}

I thank Department of paediatrics for their support for doing this project.

\section{References}

Ayman Johargy, Hani Ghazi, Aiman Mumenah. 2010. J. Pak. Med. Assoc., Vol. 60, No. 6.

Bahl, R., et al., Ray, P., Subodh, S., Shambharkar, P., Saxena, et al. 2005. Incidence of severe rotavirus diarrhea in New Delhi, India, and $G$ and $P$ types of the infecting rotavirus strains. J. Infect. Dis., 1(192): 114-119.

Barnes, G.L., Uren, E., Stevens, K.B., Bishop, R.F. 1998. Etiology of acute gastroenteritis in hospitalized children in Melbourne, Australia, from April 1980 to March 1993. J. Clin. Microbiol., 36: 133-138.

Bass, C.W., Dorsey, K.N. 2004. Rotavirus and other agents of viral gastroenteritis. In Nelson Textbook of Pediatrics. Edited by STS Reference No. 2014-03172 Page 25 Richard E and Behrman F. Raven Press, Philadelphia. 107-110.

Bassani, D.G., Kumar, R., Awasthi, S., Morris, S.K., Paul, V.K., et al. 2010. Million Death Study Collaborators. Causes of neonatal and child mortality in India: a nationally representative mortality survey. Lancet, 376: 1853-60.

Bettina, Essers, et al. 2000. Clin. Infec. Dis., 30: 192-6.

Black, R.E., Cousins, S., Johnson, H.L., Johnson, H.L., Lawn, J.E., Rudan, I., et al. 2010. Global, regional, and national causes of child mortality in 2008: a systematic analysis. Lancet, 375: 196987.

Bon, F., Fascia, P., Dauvergne, M., Tenenbaum, D., Planson, H., Petion, A.M., et al. 1999. Prevalence of group A rotavirus, human calicivirus, astrovirus, and adenovirus type 40 and 
41 infections among children with acute gastroenteritis in Dijon, France. J. Clin. Microbiol., 37: 3055-3058.

Broor, S., Singh, V., Venkateshwarlu, Gautam, S., et al. 1985. J. Diarrhoeal Dis. Res., 3: 158-61.

Brown, D.W., Mathan, M.M., Mathew, M., Martin, R., et al. 1988. J. Clin. Microbiol., 26: 2410-4.

Centers for Disease Control and Prevention (CDC). 2008. Rotavirus surveillanceworldwide, 2001- 2008. MMWR Morb. Mortal. Wkly. Rep., 57: 1255-7.

Chatterjee, B., Husain, M., Kavita, Seth, P., et al. 1996. J. Trop. Pediatr., 42: 207-10.

Editorial: New vaccines: A global vaccine for a global disease -an end to rotavirus diarrhea. 1997. CVI Forum No. 14, WHO, Geneva, p. 2-6.

Jain, V., Parashar, U.D., Glass, R.I., Bhan, M.K. 2001. Ind. J. Pediatr., 68: 85562.

Jane, S., Nakawesi, et al. 2010. BMC Pediatrics, 10: 69.

Kelkar, S.D. 1994. Present status of rotavirus vaccine. Ind. Pediatr., 31: 957-69.

Nath, G., Singh, S.P., Sanyal, S.C. 1992. Childhood diarrhoea due to rotavirus in a community. Ind. J. Med. Res., 95(4): 259-62.

Parashar, U.D., Burton, A., Lanata, C., Boschi-Pinto, C., Shibuya, K., Steele. D., et al. 2009. Global mortality associated with rotavirus disease among children in 2004. J. Infect. Dis., 200: S9-15.
Patwari, A.K., Srinivasan, A., Diwan, N., Aneja, S., et al. 1994. J. Trop. Pediatr., 40: 214-8.

Phukan, A.C., Patgiri, D.K., Mahanta, J. 2003. Rotavirus associated acute diarrhoea in hospitalized children in Dibrugarh, north-east India. Ind. J. Pathol. Microbiol., 46: 274-8.

Ram, S., Khurana, S., Khurana, S.B., Sharma, S., Vadehra, D.V., Broor, S. 1990. Bioecological factors and rotavirus diarrhoea. Ind. J. Med. Res., 91: 167170.

Selim, Ahmed, et al. 2009. Iranian J. Paediatr., 19(2): 107-116.

Versalovic, J., Carroll, K.C. 2011. Manual Clin. Microbiol., 10th ed. Washington, D.C: American Society of Microbiology Publishing. pp. 14561469.

World Health Organization. 2005. The Treatment of Diarrhea: A Manual for Physicians and Other Senior Health Workers, 4th ed. Geneva: World Health Organization.

Zafer Kurugol, Seda Geylani, Yeper Karaca, Feyza Umay, Selda Erensoy, Fadyl Vardar, et al. 2003. Turkish J. Pediatr., 45: 290-294.

Zheng, B.J., Ma, G.Z., Tam, J.S.L., Lo, S.K.F., Hon, M., Lam, B.C.C., Yeung, C.Y. 1991. The effects of maternal antibodies on neonatal rotavirus infection. Pediatr. Infect. Dis. J., 10: 865-868.

\section{How to cite this article:}

Santhoshini Vaijinath, Sangeetha, S., Prakash, R. and Lakshminarayana, S.A. 2016. Rotaviral Diarrhoea in Children Less than 5 years with Reference to their Vaccination Status in a Tertiary Care Hospital. Int.J.Curr.Microbiol.App.Sci. 5(3): 206-211. doi: http://dx.doi.org/10.20546/ijcmas.2016.503.025 